\title{
"La peor plaga que pudo haber traído la locomotora". Prostitución y control estatal en un Territorio Nacional Norpatagónico: Río Negro 1880-1920
}

\author{
María Elba Argeri \\ Instituto de Estudios Histórico Sociales Profesor "J.C.Grosso" \\ Universidad Nacional del Centro de la Provincia de Buenos Aires.
}

Se abordan las contradicciones que emergieron en el Territorio Nacional del Río Negro entre 1880 y 1920, a raíz de la pretensión del poder federal de imponer la regulación del comercio sexual en los territorios recién conquistados. Dicha imposición desencadenó diferentes instancias conflictivas que permiten desvelar procesos sociales muy complejos en la consolidación de las instituciones federales, una vez conquistada la Patagonia. Surge, así, un proceso histórico contradictorio, en el cual tuvieron un peso decisivo la existencia de múltiples mecanismos y juegos de poder, que se daban a nivel local en el mismo momento de formación de los sectores dominantes y subalternos del territorio.

En este contexto, las medidas adoptadas para el disciplinamiento de las mujeres no sólo tenían como fin la sumisión de género según las pautas de la ideología dominante, sino que se inscribían en el proceso histórico de transformación de aquellas pautas culturales tradicionales en la región que fuesen disfuncionales para el nuevo modelo de dominación.

Vehículo para la catarsis pública y la represión privada de las fantasías eróticas, espejo sórdido de la exclusión étnica y social y de la sumisión de género, la prostitución reglamentada es una excusa temática para iluminar diferentes aspectos de los procesos de configuración de la física política. En el presente trabajo intentaremos abordar un aspecto restringido de esta perspectiva, vinculada a la dinámica orden-desorden-orden que implicó el proceso de regulación de la prostitución por parte de los poderes públicos en Norpatagonia, en el contexto histórico de formación y consolidación del poder estatal en el Territorio Nacional del Río Negro.

La documentación oficial y periodística, atravesada por diferentes discursos, deja al descubierto la estrecha vinculación que existió entre la necesidad de reglamentar la prostitución y la implementación de otras medidas que, afectando directamente a las mujeres, tenían por objeto el logro de un amplio disciplinamiento social, en el mismo momento de conformación de

1 Para una mayor compresión de esta perspectiva de análisis ver Foucault, Michel: La vida de los hombres infames. Ensayos sobre desviación y dominación, Madrid, 1990. 
los sectores subalternos. En este sentido, las medidas que se adoptaron desde los poderes públicos fueron, siempre, funcionales al modelo de dominación que pretendía imponerse y, por tanto, uno de los pilares del orden social.

No obstante, en la mayoría de los discursos dominantes de la época —en sus diferentes vertientes ético-religiosas o profilácticas- el comercio sexual, aun reglamentado, aparecía como un elemento perturbador del orden: subversivo a los ojos del poder. Y los prostíbulos, considerados para esta lógica un "mal necesario", eran percibidos como los centros generadores de la mayor transgresión, donde se difundían las prácticas de la "mala vida", contrarias a la disciplina laboral. Efecto no deseado de la primera faz del disciplinamiento, que será corregido con posterioridad, cuando legalmente el comercio sexual se torne incompatible con la sociabilidad.

Pero esta aparente contradicción que muestran las primeras instancias de la imposición del "orden" no está presente en la letra de las ordenanzas y reglamentaciones. Los documentos son muy claros al respecto, ya que establecen una nítida línea divisoria entre prostitución clandestina y prostitución reglamentada. Sólo esta última era, aunque condenada moralmente, jurídicamente aceptada.

La denominada prostitución clandestina englobaba diferentes prácticas culturales que pretendían erradicarse y que, en este contexto, se tornaron expresiones de rechazo a la imposición de: la cohabitación monogámica, el matrimonio legalizado, el comercio sexual regulado. En efecto, el comercio sexual libre era, indiscutidamente, subversivo para el establecimiento del orden: no pagaba impuestos y la mujer no se sometía a las reglas del trabajo sexual esclavizado, pautado por el estado. La venta de servicios sexuales libres tenía reglas similares a las de la venta permanente u ocasional de fuerza de trabajo. Y en áreas rurales constituía un complemento económico monetario o en especie, que se sumaba a las ganancias obtenidas por otras actividades que realizaban los miembros de los grupos domésticos (labranza, cría de ganados, tejeduría, comercio al menudeo), con el fin de escapar, aunque sólo fuese temporalmente, a la proletarización. En este sentido, su penalización tenía por objeto volcar la oferta de fuerza de trabajo hacia otros sectores de la economía. Y tratándose de trabajo femenino, en una sociedad con clara tendencia discriminatoria de las mujeres (discriminación de género que se sumaba a la étnica y social), esto implicaba contar con un fuerte contingente de brazos para lo que se denominaban "tareas de su sexo" (el trabajo doméstico). Así fue que la dicotomía prostitutas-sirvientas, que aparece con mucha frecuencia y de mane- 
ra explícita, deja al descubierto uno de los aspectos centrales del problema. Sin lugar a duda, su faz más conflictiva.

Por esto, la profesionalización de la prostitución reducía o circunscribía notablemente la dispersión material del conflicto, estrechando el espacio físico sometido a control estatal. La prostituta dejaba de ser una trabajadora libre o una pequeña comerciante para convertirse en una mercancía-esclava, que permitía capturar ganancias que discurrían por diferentes canales. Al mismo tiempo que el prostíbulo, espacio cerrado a la visión externa, limitaba — según los diferentes discursos- la difusión de las enfermedades y el ejercicio del "pecado". Se imponían los márgenes en donde la pasión podía expresarse sin culpas. De tal manera que los habituales desbordes de los clientes se inscribían en el juego pautado de la catarsis habitual que preservaba a la familia.

En el estado actual de la investigación es muy difícil establecer con qué grado de profundidad y aceptación se impuso la cosmovisión éticojurídica de la sociedad blanca, que imponía de hecho una reconstrucción dicotómica del género: decentes-disciplinadas; indecentes-indisciplinadas. ${ }^{2}$ Por otra parte, no existen investigaciones específicas sobre las prácticas sexuales de las sociedades indígenas que habitaban los territorios del sur. Tampoco sabemos si existió algún tipo de prostitución religiosa en estas sociedades. Esta carencia del conocimiento nos impide reflexionar sobre las posibles resignificaciones que pueden haber tenido las prácticas sexuales una vez que la Patagonia se transformó en una zona receptora de migrantes.

¿Que significaba ejercer la prostitución para una mujer indígena o mestiza? ¿En qué medida las uniones sexuales y las pautas de cohabitación implicaban una transgresión a las normas culturales? Y si esto era así, ¿de qué pautas culturales se trataba? En este contexto sociocultural, con profundos procesos de mestizaje, consideraremos ejercicio de la prostitución solamente el comercio sexual circunscrito al ámbito mercantil de los prostíbulos, modalidad que fue impuesta por los pobladores blancos y que se vinculó, en alguna medida, con los circuitos nacionales (¿e internacionales?) de migración forzada de mujeres. En la Patagonia los prostíbulos se asientan primero en las zonas portuarias - tanto sobre el Atlántico como sobre el Pacífico-, incluso antes de llevarse a cabo las campañas militares

2 El "género" siempre tiene una definición específica que depende de cada configuración social, es una relación histórica, cultural y lingüísticamente construida. Chartier, Roger: "Différences entre les sexes et domination symbolique", en Annales, 4, París, julio-agosto 1993. 
argentino-chilenas. Práctica mercantil que se difundió, luego, hacia el interior, según el trazado de las líneas del ferrocarril, a medida que el espacio se iba ocupando efectivamente. ${ }^{3}$

Pero la incorporación del lejano sur a la dinámica de los circuitos de comercialización sexual trajo aparejados una serie de nuevos conflictos y contradicciones, generando una nueva instancia de "desorden". En efecto, la documentación muestra las diferentes etapas de la confrontación y los sujetos que estuvieron inmersos en este tipo de disputas. Así, entre 1900 y 1910 transcurre la etapa de mayor conflictividad porque: se dictaron los primeros reglamentos; se fundaron los primeros prostíbulos, muchos de los cuales funcionaban en casas particulares y comercios regentados por mujeres nativas o inmigrantes chilenas, dedicadas a la actividad mercantil, al menudeo; se clausuraron los prostíbulos a petición de los vecinos más importantes de las diferentes localidades; se estableció un estricto control de la moral privada, condenándose el concubinato y las uniones sexuales libres; se repartían los menores en las casas "decentes" y conventos de la Orden Salesiana, argumentando los malos ejemplos que recibían de los grupos familiares.

Finalmente, después de la Primera Conferencia de Gobernadores de los Territorios Nacionales en 1913, y con la posterior asunción de los gobiernos radicales, el tema de la prostitución reglamentada ya no fue discutido. La resolución de la anterior conflictividad permitió la institucionalización de un nuevo "orden", y por tanto un mayor afianzamiento del poder estatal, hacia 1920.

\section{El marco del conflicto: la reglamentación y el disciplinamiento de las mujeres}

En los territorios nacionales, la preocupación por establecer los códigos de una moral pública común y aceptada por el conjunto de los pobladores implicaba establecer pautas culturales fundantes del orden, útiles al modelo económico y político que pretendía imponerse: matrimonio

3 El comercio sexual vinculado a la práctica de la migración forzada de mujeres seguía el trazado ferroviario. Para el Territorio Nacional de La Pampa, ver María H. Di Liscia, María S. Di Liscia y Ana M. Rodríguez: "Prostíbulos y control estatal en el Territorio Nacional de La Pampa", en Lidia Knecher y Marta Panaia (comp.): La mitad del País. La mujer en la sociedad argentina, Buenos Aires, 1994. 
monogámico, disciplinamiento para el trabajo asalariado, aceptación de las obligaciones fiscales, control de la violencia, reglamentación del comercio sexual, etcétera. Dicho de otra manera, establecer el disciplinamiento social y cultural de varones y mujeres. ${ }^{4}$ Obligación que competía a los funcionarios y agentes estatales, en quienes recaía la tarea material del control social.

Dentro de estos parámetros se dio una especial atención al disciplinamiento de las mujeres, tal como se observa en las fuentes. En este caso la moral pública implicaba mucho más que la simple reglamentación del comercio sexual, abarcando el conjunto de las transformaciones sociales. En trabajos anteriores hemos estudiado de qué manera el disciplinamiento sexual de las mujeres implicaba, al mismo tiempo, disciplinamiento económico y político. ${ }^{5}$ Los esfuerzos para imponer progresivamente el matrimonio legal, monogámico, tuvo por finalidad desestructurar a los grupos domésticos, tanto en sus relaciones materiales como en su reproducción cultural, marcando el inicio del proceso de proletarización. De esta manera, la instauración de la prostitución reglamentada fue funcional a las estrategias de control social por parte del estado, y por tanto a la profundización del modelo de dominación.

En este contexto, la reglamentación de la prostitución estuvo influida por: los discursos al uso, contradictorios entre sí —higienistas y católicos-; los avatares del juego político - debido a la mayor o menor influencia de la Iglesia Católica sobre el gobernador y funcionarios de turno-; la sanción de leyes nacionales; las presiones de los embrionarios grupos dominantes locales. Más aún, las diferentes instancias que condujeron a la imposición de la prostitución circunscrita al espacio de los prostíbulos - acompañada por una serie de reclamaciones para su prohibición, erradicación o legalización - permite iluminar el conjunto de la sociedad en sus diferentes contradicciones, en un período temporal que se caracterizó por cambios muy profundos: el fin de la sociedad de frontera y la conformación de una sociedad socialmente diferenciada.

La Ley 1532, más conocida como Ley Orgánica de los Territorios Nacionales, facultaba a los respectivos gobernadores para tomar las medidas que considerasen pertinentes para el "fomento" de la jurisdicción a su

4 Argeri, María E.: "Estado Nacional y proceso de subordinación estatal en Norpatagonia, 1880-1930", ponencia presentada en el Simposio "Estado nacional, Elites y Cuestión Regional", Tucumán, abril de 1996.

5 Argeri, María E., y Sandra Chía: "Estado Nación y vida cotidiana: la mujer de "bajo pueblo" en Norpatagonia, 1880-1930", ponencia presentada en las Jornadas de Investigación en Ciencias Sociales, Jujuy, octubre de 1994. 
cargo. Pero ninguna normativa se sancionaba sin el consenso entre éste y el consejo de gobierno - cuerpo colegiado que comenzó a funcionar en Río Negro con los gobiernos civiles- constituido por los vecinos más prominentes del territorio, residentes en Viedma. En este bloque político, garante del consenso, emergían las normativas específicas para el territorio. Así se dictaron los reglamentos que ordenaban y restringían el ejercicio del comercio sexual a los prostíbulos patentados. Estos debían cumplir con las disposiciones emanadas de la jurisprudencia: local adecuado, control sanitario y pago de impuestos. De tal manera que el comercio sexual era regulado por el ejecutivo territorial y controlado por las municipalidades (o en su defecto por las sociedades de fomento) y la policía, en quien recaía la misión de hacer cumplir las normas. Poderes que en más de una oportunidad se enfrentaron por la pretensión de ingerencia excluyente de los funcionarios en las cuotas impositivas, tanto legales como ilegales, que se cobraban a este tipo de actividad.

Ahora bien, limitando el análisis al plano prescriptivo, quedan en evidencia las marchas y contramarchas que tuvieron lugar durante la primera década del siglo XX, para aceptar finalmente la existencia de los prostíbulos como medida de "profilaxis social". Así, en algunos momentos se aceptaban los prostíbulos para disciplinar el comercio sexual libre y las uniones maritales no legalizadas y mucho menos consagradas. Luego se prohibían, bajo la excusa de la falta de médicos y hospitales adecuados para curar las enfermedades venéreas. Finalmente, nuevas presiones llevaban a su reapertura. Este conflicto se desata entre 1898 y 1913. Observemos los discursos que organizaban y desorganizaban las prácticas de la vida cotidiana al compás de las propias contradicciones que tenían lugar en el seno del bloque en el poder.

Del 5 de febrero de 1898 data la siguiente resolución, que prohibía la prostitución clandestina. La firmaba el gobernador Tello, funcionario que tenía estrechas vinculaciones con los miembros de la Iglesia Católica:

“...El gobernador del Territorio: Teniendo en vista: que según el Censo Nacional de 1896 (sic!), este pueblo tiene, 1456 habitantes, los que en su casi totalidad forman familias organizadas; que el Presbítero D. Evasio Garrone está autorizado por el Consejo Nacional de Higiene para ejercer la medicina y en tal concepto es el médico de las nueve décimas partes de la población, encontrándose de consiguiente habilitado para conocer el estado de la salud pública: que a su vez el médico de la Gobernación doctor Pérez Font está en análogas condiciones para poder apreciar esto mismo; y considerando: 1) que según informe escrito de la policía, existen varias mujeres de vida airada con casas clandestinas, sustrayéndose a la ley de trabajo 
honesto, por cuyo motivo también falta el servicio doméstico 2) Que según informes de los dos médicos expresados, la juventud del sexo masculino desde los catorce años de edad salvo excepciones, está con tal motivo contaminada, en deplorable estado de salud, inútil para la actividad social. 3) Que esta clase de casas clandestinas, aun cuando no se note peligros para la salud, están prohibidas en todo país culto, pudiendo citarse como ejemplo a la Capital Federal. 4) Que es tanto más grave el escándalo, por tratarse de una pequeña población con familias distinguidas de ejemplar moralidad, que se ven obligados a vivir en presencia de ese repugnante comercio, el que en centros populosos pasa desapercibido, lo que indujo a algunos gobernadores de provincias poco pobladas, a prohibir el establecimiento de semejantes casas, aun de las sujetas a inspección médica. 5) Que si ahora mismo se tolera una casa pública de esta naturaleza, sujeta a la vigilancia médica, no daría el resultado apetecido, desde que, según lo expuesto, actuarían los mismos elementos contaminados sin poder evitarse el mal, aunque se habilitara una sala para tales enfermedades, lo que por otra parte no es posible, desde que el presupuesto no destina fondos a este objeto, de donde resulta que si la municipalidad les impusiera patente lo que implicaría permiso para su establecimiento; la Policía de su parte, sin atacar la Ordenanza, les prohibiría el comercio, una vez que legalmente se constatara la mala salud de esas personas. 6) Que el Consejo de Gobierno formado de un encumbrado sacerdote y de diez respetables padres de familia, los cuales cuatro son los comerciantes más fuertes de esta plaza, y los demás son altos empleados de la Nación o territorio, han acordado unánimemente la clausura de dichas casas. 7) Que por el artículo 7, inc. 2 de la Ley Orgánica de los Territorios Nacionales, el Gobernador está en el deber de dictar reglas convenientes de carácter administrativo. Por tanto: RESUELVE: Art. 1. ${ }^{\circ}$ Se prohíben los prostíbulos clandestinos. Art. $2 .^{\circ}$ La infracción se penará con diez pesos diarios de multa por persona. Art. 3. ${ }^{\circ}$ La policía no autorizará el establecimiento de prostíbulos patentados, por no ser de su incumbencia, por no tolerarlo la poca densidad de la población, ni ser honestos...”. 6

Orden y preservación de la familia ("organizada") en sus condiciones morales y sanitarias. Los miembros del Consejo de Gobierno que avalan esta resolución se arrogan el derecho de establecer los límites para el comercio sexual. Queda asimismo al descubierto otro problema: la independencia con que opera el personal policial respecto de las infracciones y transgresiones a la ley (problema sobre el que volveremos oportunamente).

Por estos años, las diferentes comisiones municipales del territorio dictaban reglamentos análogos, tomando como base la resolución anterior. Todos ellos son una copia fiel del que dictó en 1875 el Concejo Deliberante de la ciudad de Buenos Aires, cuando se autorizaron los burdeles. ${ }^{7}$ En ellos

6 Archivo Histórico de la Provincia de Río Negro (en adelante AHPRN), Gobernación, UD 2075/1898. Reglamento sobre prostitución. (La cursiva es nuestra).

7 Guy, Donna J.: El sexo peligroso. La prostitución legal en Buenos Aires, 1875-1955, Buenos Aires, 1994, pág. 67. 
constan los siguientes puntos: sobre los requisitos para las casas de prostitución, sobre las obligaciones de las prostitutas y "madamas", conjuntamente con un capítulo especial dedicado a disposiciones generales, donde, entre otras obligaciones, figura el pago de las tasas e impuestos correspondientes. El marco ideológico de estas resoluciones siempre quedaba a mitad de camino entre la moral y la higiene, con mayor o menor peso de una u otra perspectiva:

“...los escándalos que pueden producirse por la instalación de las casas de prostitución dado lo reducido de la población, queda salvado en este pueblo por lo retirado que aquella está situada, aún más, en esta localidad existen numerosas mujeres que están agregadas a soldados, cuya vida inmoral es preocupación constante...”»

Por su parte, la Resolución Reglamentaria de 1901, dictada por el gobernador Tello y firmada por el secretario R. Sarmiento contradice la de 1898. Se clausuran los prostíbulos,

“...que tampoco podría invocarse la conveniencia de tolerar la existencia de dicha en este lugar, porque en Patagones (Provincia de Buenos Aires) que está a 370 metros de este pueblo, existe una patentada, que habiendo impuesto al Gobernador el art. 7 inc. 2 de la Ley Orgánica de los Territorios Nacionales el deber de dictar ordenanzas convenientes para el fomento de los mismos, no puede permitirse que se conspire públicamente contra la salud de sus habitantes y el porvenir de las familias, que es tanto más grande el escándalo por tratarse de una pequeña población con familias distinguidas de ejemplar moralidad, que se ven obligadas a vivir en presencia de ese repugnante comercio, el que en ciudades populosas pasa desapercibido, lo que indujo a algunos gobernadores de provincias poco pobladas, a prohibir el establecimiento de esas casas, aún las sujetas a inspección médica... que entre la disyuntiva de complacer a la mayoría de los habitantes que quieren la clausura... y entre la minoría no es dudosa la elección... El Gobernador del Territorio RESUELVE, Art. 1. La policía impedirá el ejercicio de la prostitución en el prostíbulo de este pueblo, y en cualquier otro del Territorio..."”

El mismo gobernador Tello dicta en 1905 otra resolución que vuelve a condenar la prostitución clandestina, por ser causante de la propagación de diferentes enfermedades,

“...De lo contrario se habrán defraudado los anhelos del Gobierno Nacional que propende a la formación de una sociedad vigorosa en la inmensidad de esas regiones, que

8 AHPRN, Municipalidad UD 4334/1901. Carta del presidente de la Corporación Municipal de General Roca, al gobernador. (La cursiva es nuestra).

9 Ibídem, Policía, UD 8309/1901. Resolución del gobernador frente a una queja del dueño del prostíbulo de la localidad de Buena Parada. (La cursiva es nuestra). 
tienden a poblarse rápidamente, ensanchando el progreso de los Territorios Nacionales, que han dado en llamarse la $2{ }^{a}$ República, de nuestro país, para su integridad nacional, y acrecentamiento de la riqueza pública, como también de la moralidad. Y si desgraciadamente no se adoptasen medidas severas de profilaxis, es mi convicción que este verdadero flajelo (sic!) será uno de los factores propicios para la corrupción y para engendrar una raza degenerada; aparte de que tendremos personas inútiles para el matrimonio y para la actividad social (.) Los casos de estas enfermedades secretas, que son por su naturaleza infectocontagiosas, tienen aquí el agravante de que se vienen multiplicando, y son estas casas una de las causas eficientes... las cunas del alcoholismo y de la tuberculosis..."

Esta aparente política errática con respecto a qué hacer con la prostitución obedecía a las disputas que, en el plano local, se establecían entre los funcionarios, más o menos influenciados por los discursos católicos y liberales. Y también porque se intentaba — durante la primera década del siglo- transformar las prácticas culturales de los sectores de "bajo pueblo", tratando de no agregar más posibilidades para el "indisciplinamiento".

Conjuntamente con el problema de la regulación de la prostitución, los funcionarios públicos estaban preocupados por disciplinar otras prácticas. La documentación oficial es muy abundante respecto de las mujeres que vivían sin marido, ya sea conocido o ausente; en concubinato; con una extensa prole sin padres presentes; o con agregados masculinos rotativos. Todas estas imputaciones servían para que la policía, los jueces de paz y los defensores de menores, permitiesen la radicación de los menores en las casas de las familias "decentes", o en su defecto, en los conventos y colegios de la orden Salesiana, donde se dedicaban a oficios varios. El reparto indiscriminado de la mano de obra infantil llegaba hasta la capital federal y hasta otros puntos alejados del país. De igual modo, la mujer que abandonaba a su marido o concubino era considerada en falta, obligada a retornar al hogar, o de lo contrario, era enviada a cumplir condena, recluida en las instituciones de la Iglesia (Desde 1894, la orden Salesiana fue cárcel para mujeres y menores. En 1919 se fundó la cárcel estatal para mujeres). En todos los casos las imputaciones hacían referencia a la "corrupción de menores". Detrás de esta figura jurídica se desarticulaba a los grupos domésticos, quitándoles los brazos necesarios para mantener una economía autónoma. ${ }^{11}$

10 Ibídem, Policía, UD 13114/1905. Considerandos del médico Humble, inserto en la resolución del gobernador. (La cursiva es nuestra).

11 Para una mayor comprensión del problema ver Argeri, María E.: "Sociabilidad 'pecaminosa", Ponencia presentada en V Jornadas Interescuelas y departamentos de Historia y I Jornadas Rioplatenses Universitarias, Montevideo, septiembre, 1995. 
La situación cambia —como ya lo señaláramos— luego del año 1913. A partir de este momento se establece que la apertura y cierre de los prostíbulos sería en todos los casos autorizada por el gobernador, bajo requisitos muy precisos de higiene y orden, prohibiéndose el baile y el despacho de alcohol. En el apartado población femenina del resumen de la citada Conferencia se establece:

“...1. ${ }^{\circ}$, que para la provisión de empleos en los Territorios Nacionales, tanto del personal superior como del subalterno, sean preferidas las personas con familia. 2. ${ }^{\circ}$ Que se procure el envío... de menores del sexo femenino para ser colocados en las casas de familia y establecimientos industriales. $3 .^{\circ}$ Que las mujeres condenadas a deportación, cumplan su condena en los Territorios Nacionales, cuando los gobernadores demuestren la conveniencia de que se instalen en sus respectivos Territorios. 4. ${ }^{\circ}$ Que se constituya una Sociedad Filantrópica que propenda al establecimiento en los Territorios de industrias que utilicen preferentemente el trabajo de la mujer..." ${ }^{\prime 2}$

La fuente es demasiado elocuente. La deportación femenina legalizó la incorporación de la Patagonia (y de los otros territorios nacionales) al comercio de migración forzada de mujeres. Este tráfico representó una competencia feroz para las pequeñas comerciantes independientes, que "arranchadas" convertían su casa en una fonda, un lugar para ir a divertirse o a consumir, eventualmente, servicios sexuales.

Luego de 1913 ya nadie discute sobre la "necesidad" de abrir prostíbulos, porque servían para contrarrestar,

“...la corrupción que existe en el elemento bajo de la población, donde sin que sea posible evitarlo, se ejerce una prostitución clandestina sin fiscalización médica...”13

Desde entonces se cerraban por orden de la gobernación, todos los despachos de bebidas, fondas y casas de comercio al menudeo, regenteadas por mujeres, y sin patente. La nómina de pequeñas comerciantes era remitida por la policía. Y la imputación por "prostitución clandestina" reemplazó a la anterior por "malos ejemplos y corrupción de menores". Al mismo tiempo, a la mayor parte de las mujeres naturales del territorio no se les permitió ser dueñas o "madamas", y salvo en contadas ocasiones fueron, temporalmente, pupilas de los nuevos prostíbulos. Las nativas y las inmigrantes pobres radicadas desde hacía mucho tiempo tenían pocas opciones legitimadas: el servicio doméstico, el matrimonio legalizado, la deportación, la cárcel.

12 AHPRN, Territorios Nacionales, Leyes y Decretos, Buenos Aires, 1914, pág.185.

13 Ibídem, Gobernación, Exp. 6877/1927, pág. 11. 


\section{Prostíbulos y prostitutas}

Los ámbitos donde se ejercía la prostitución en la Norpatagonia no estaban adornados con brocados, alfombras y lámparas, ni tenían baldaquinos en las habitaciones. Distaban mucho de los lujosos burdeles de Buenos Aires, Montevideo o Rosario. Tampoco se parecían a los hacinados conventillos de las grandes ciudades que han sido tema recurrente de la literatura y el cine. En la Patagonia, la escasez de habitantes no daba lugar para grandes hacinamientos, a pesar de que muchas veces se viviera en condiciones higiénicas precarias y, hasta en algunos casos, deplorables. Así, en caso de incorporarse nuevas pupilas, la vivienda se podía ampliar agregando otra habitación de adobe, o construyendo un tabique de madera que subdividiera los espacios existentes.

En efecto, los prostíbulos de categoría fueron inexistentes. La gran mayoría funcionaba en ranchos y en casas tipo "chorizo", en los límites de la zona urbana, sin servicios públicos, expuestos a las inclemencias del tiempo y de la inhóspita geografía. Pero, no obstante las escasísimas comodidades, éstas eran muchas veces superiores a las que los clientes habituales estaban acostumbrados:

“...En cuanto a las piezas ocupadas por las pupilas inclusive la regenta ninguna de ellas estaba en condiciones higiénicas; si se tiene en cuenta que a la mayoría no solo le hace falta una mano de blanqueo sino que le falta parte del reboque. El cielo raso de las mismas que es de madera no tiene ni nunca se le ha dado una mano de aceite lo que provoca a que insectos como ser arañas, cien pies y alacranes se estacionen en ellos con el consiguiente peligro para las mismas pupilas... La cocina sita dentro del mismo y único patio, no tiene piso de mosaico ni madera, es de tierra y húmedo, mide dos metros más o menos de ancho por tres de largo, sobre la mano izquierda mirando hacia la puerta de entrada de la misma sale un desagüe que va a dar a un terreno frente a una casa de familia con la consiguiente molestia para esta debido al olor pestilente de las aguas servidas... tiene dos letrinas sin inodoro ni videt; piso de madera y en malísimas condiciones de blanqueos y reboque, el cual le falta desde medio metro hacia arriba del nivel del piso... cuarto de baño no tiene... el comedor se encuentra en regulares condiciones aunque es muy reducido... el patio en su conjunto se encuentra en malísimas condiciones de higiene máxime si se considera que es depósito de leña, cajones vacíos, latas y otros desperdicios. Finalmente las pupilas aprovechan para desocupar los recipientes de sus aguas servidas no solo en el desagüe de que hice referencia sino hasta en el mismo patio. No está de más que haga constar que la cocina y el comedor están a muy escasa distancia de las letrinas...."14

14 Ibídem, Gobernación, Exp.4973/1925, 5. 
A las condiciones insalubres del edificio se agregaban muchas veces,

“...que en varias ocasiones encontrándose la diciente menstruando la patrona le ha permitido trabajar... que no tiene espéculo por habérsele roto; utilizando cuando toca la inspección médica uno propiedad de la patrona...”15

Las empleadas de los prostíbulos debían pagar con su salario,

“...la venta de ropa por parte de la aludida regente... como ser medias y juegos de ropa interior, a más jabones y otros efectos como kerosene..."16

La reglamentación de la prostitución generó un mejoramiento en las condiciones de higiene. Inspecciones sanitarias semanales realizadas por el médico, o en su defecto por el boticario del pueblo, obligaban al uso de la libreta sanitaria o al envío de la enferma, preferentemente, al hospital de Bahía Blanca. Asimismo, para instalar un prostíbulo era imprescindible contar con un local adecuado para conservar un mínimo de privacidad. Estos requisitos sólo podían ser satisfechos por un comerciante que contase con un cierto capital.

De esta manera se expulsó del mercado sexual a las pequeñas comerciantes (en su mayor parte nativas o chilenas), quienes valiéndose de las primeras ordenanzas que permitían la instalación de burdeles, transformaron sus despachos de bebidas en casas de prostitución, muchas veces bajo el rótulo de fondas. Estos comercios funcionaban sin patente y con el solo permiso del comisario.

Pero hacia 1920 el gobernador clausuró todos los burdeles independientes, luego de exigir la nómina de alrededor de veinte mujeres comerciantes. De ahí en adelante, los prostíbulos serán provistos exclusivamente por vía externa. La rotación periódica de las prostitutas, que exigía este tipo de tráfico, tampoco dejó mucho margen para que las mujeres residentes en la región pudiesen incorporarse como pupilas.

Los circuitos que abastecían a la Patagonia no se han podido reconstruir por el momento. No obstante existen indicios que muestran la existencia de empresas familiares, que operaban entre Buenos Aires y los puertos o las terminales del ferrocarril. Las embarcadas en Buenos Aires con destino al sur eran acompañadas por algún miembro de la red mercantil. El tráfico de mujeres se disimulaba declarando que eran sirvientas, cama-

15 Ibídem, Gobernación, Exp.4973/1925, 8.

16 Ibídem, Gobernación, Exp.4973/1925, 7. 
reras o modistas. Los prostíbulos estaban, siempre, regentados por mujeres. Eran en su gran mayoría extranjeras - españolas, rusas e italianas-. En cambio las pupilas eran argentinas, presumiblemente originarias de los otros territorios nacionales, y cuya edad es casi imposible establecer con certeza. En todos los casos dicen tener más de dieciocho y menos de veinticinco, agregándose años por las exigencias legales (no estaba permitida la incorporación de menores de dieciocho años), o quitándoselos por las condiciones de la demanda.

\section{La segunda instancia del conflicto: los poderes locales y el personal policial}

En 1910, una carta firmada por treinta y seis vecinos "decentes" del pueblo de Valcheta - ubicado en la meseta rionegrina, zona de mayor concentración de la población indígena y mestiza-, era enviada al gobernador del territorio. Solicitaban el cierre del primer prostíbulo que se había abierto en la localidad. El contexto ideológico en que se enmarcaba tal petición -incluyendo la perspectiva ético-profiláctica, redefinida para el nuevo contexto - reflejaba aspectos del sentimiento localista, que comenzó a perfilarse nítidamente en el Territorio Nacional del Río Negro a principios del siglo XX.

"Los que suscriben vecinos del Pueblo y Colonia de Valcheta ante V.S. se presentan respetuosamente y piden: quiera ordenar la clausura del prostíbulo recientemente instalado en el pueblo... por ser atentatorio contra la salud pública... No vamos a entrar en detalles que la decencia prohíbe discutirlos, pero bástele saber al Sr. Gobernador, que aquí no tenemos médicos que pudieran poner trabas a la peor de las plagas que pudo haber traído la locomotora". ${ }^{17}$

Alrededor de la misma fecha otras cartas y telegramas conteniendo idéntica petición y del mismo tenor eran remitidas a la gobernación:

“...los grandes anhelos que tendríamos de ver clausurada la casa 'non santa' que actúa en este pueblo (Conesa)... el poco adelanto que atrae a esos pueblos la existencia de estas casas..."18

17 Ibídem, Policía, UD 15110/1910 (Carta al gobernador, con 36 firmas de los vecinos más prominentes de la localidad de Valcheta).

18 Ibídem, Policía, UD 13050/1908. Telegrama del cura párroco de Conesa al gobernador. 
"Los que suscriben vecinos todos de esta localidad ante V. E. respetuosamente se presentan y exponen: que de común acuerdo protestan el lamentable hecho de haberse estanciado en el centro de este pueblo una casa de tolerancia... solicitando... el inmediato desalojo de este foco de corrupción... pedimos encarecidamente en nombre de la misma benemérita Constitución por el bienestar moral y temporal de nuestros hijos..." ${ }^{19}$

“...Ahora ya son dos las casas de prostitución establecidas una al lado de la otra a una cuadra de la Estación y en el centro de nueva población toda formada por personas laboriosas y honestas y familias que se verán el caso de retirarse si V.S. no toma las providencias del caso..." ${ }^{20}$

“...La comisión que tengo el honor de presidir... acordó negar el permiso que se solicita... por no ser de suma necesidad todavía, haciéndose además intérprete de la opinión del vecindario...."21

También en la prensa local, aparecen editoriales con idéntica concepción:

“...Comprende la plataforma de nuestro programa combatir por los medios de propaganda que disponemos todos aquellos vicios o costumbres que tiendan a hacer de la vida humana una vida impropia... no se forman hijos buenos, como no se forman los jóvenes dignos ciudadanos viviendo en los despachos de bebidas o en casas de juego y en la casa "non santa". Allí se consigue perderse para siempre..."22

En todos los casos firmaban los vecinos "decentes" de los incipientes núcleos urbanos territoriales interconectados por caminos vecinales y rastrilladas indígenas, pero comunicados con los centros urbanos de la región pampeana por medio del ferrocarril. Emblema del progreso para las clases dirigentes argentinas, pero símbolo inequívoco del control estatal para algunos pobladores patagónicos que pretendían mantener una existencia libre e independiente frente a cualquier intromisión de un poder superior al propio. Cada una de las reclamaciones mostraba al pie de página la firma de los peticionarios: comerciantes en su mayoría, empresarios rurales, empleados y agentes del estado, curas párrocos, muchos de ellos miembros de la Sociedad de Fomento, forma embrionaria de los futuros poderes municipales. Se trataba de migrantes que una vez finalizadas las campañas militares se radicaron en la Norpatagonia con el objeto de es-

19 Ibídem, Policía, UD 16941/1911. Carta de los vecinos de Pringles al gobernador.

20 Ibídem, Policía, UD 16396/1911. Nota enviada por 27 vecinos de Cipolletti al gobernador.

21 Ibídem, Policía, UD 12067/1907. Comisión municipal de General Conesa.

22 Ibídem, El Imparcial, 12 de diciembre de 1907, n. ${ }^{\circ} 10$. 
tablecerse en una región despoblada, con abundancia de tierras fiscales, donde pudiesen sustentar una economía independiente con escasas presiones estatales.

Cartas como las que anteceden, con diferentes reclamaciones, dejan en evidencia la incipiente formación de los sectores dominantes locales, quienes para constituirse como tales necesitaban, por una parte, diferenciarse moralmente del resto de los pobladores (alegando un comportamiento moral más discursivo que práctico), mientras que, por otra, exigían del poder territorial el reconocimiento para decidir sobre la imposición de las normas que afectasen al conjunto de la población del distrito. Y en este sentido entraban muy frecuentemente en contradicción con la normativa legal que emanaba de los poderes públicos. En reglas generales, los vecinos "decentes" se oponían a cualquier medida administrativa que afectase sus intereses individuales. Al mismo tiempo elaboraban un discurso localista articulado en torno a los "males" fundamentales que llegaban por ferrocarril y eran consecuencia del "progreso": la enfermedad, la delincuencia, la usurpación de los bienes. Dicho con otras palabras: las infecciones venéreas, la llegada de nuevos migrantes permanentes y estacionales; la adopción de medidas fiscales y de nuevas mediciones catastrales. Percepción que, aunque teñida de fuertes contenidos ideológicos, no por eso se alejaba exageradamente de la realidad.

Pero la aspiración de relativa autonomía de poder que tenían estos incipientes sectores dominantes locales obligaba al ejercicio permanente de un juego político que permitiese convalidar, frente al gobernador y demás instituciones estatales, las credenciales personales para ser considerado un poblador con capacidad de decisión. No obstante, durante las primeras cuatro décadas posteriores a 1880 asistimos al desencadenamiento de una acentuada conflictividad, producto de la disputa inicial por los espacios de poder y los recursos económicos. Conflictividad que muchas veces mostraba acentuados rasgos de sordidez. Por tanto, cada vez que los representantes de los poderes públicos (gobernador, funcionarios de la justicia letrada, ejército, Iglesia) intentaban imponer normas generales, se iniciaba una cadena de quejas y reclamaciones. La red local de poder se movilizaba intentando buscar apoyo generalmente en el gobernador o, en su defecto, recurría a la práctica habitual de ventilar los problemas por medio de la prensa local y nacional.

Mientras tanto, a nivel local su poder se amparaba en el uso personal de las armas (cuya posesión no estaba prohibida por el Código Rural de los 
Territorios Nacionales de 1894) $)^{23}$ y su participación como miembros jerárquicos del personal policial (hasta la primera década del siglo XX) o su posterior vinculación con los comisarios y agentes de la policía, les permitía imponerse sobre el resto de los pobladores, alegando ser la voz de la ley. ${ }^{24}$

En el marco de estas confrontaciones locales, la reglamentación de la prostitución trajo, para los poderes públicos, una serie de consecuencias y efectos no deseados. La policía se transformó, de hecho, en el poder alternativo que interpretaba, libremente, las normas y amparaba los ilícitos. Así permitía la contraprestación de algún tipo de "coima": la existencia de prostíbulos sin patentar, la apertura de los cafés de camareras sin acuerdo del gobernador, el juego clandestino, la violación a la ley de descanso dominical. Los comercios comprometidos quedaban expuestos al libre arbitrio de los funcionarios policiales. Las inspecciones de la jefatura demuestran estas prácticas recurrentes:

“...Aída Rodríguez... ser española, de treinta y cuatro años de edad, con veintiuno de residencia en el país, dueña del prostíbulo... ha tenido despacho de cerveza y refrescos en una pieza reservada, el único... que lo sabía era el Sub Comisario Servando Campana quien le exigía la suma de 20 pesos moneda nacional por semana... le abonó... dicha cantidad todas las semanas en su despacho en la comisaría y sin la presencia de testigos..." ${ }^{25}$

“...Encontró a Carolina y al encargado de la Comisaría entonces Sargento Agustín Eviner... (este) le exigía que le diera dinero de lo contrario le haría cerrar la casa..."26 “...Adela Pagioni, italiana, de 38 años de edad, con veinte de residencia en al país... es la dueña de la casa de tolerancia... siendo su gerenta Adela Kaufman... continuamente recibe quejas de la gerenta Adela, de que el Comisario de Policía Don Alfredo A. Pietrapiana que es a quien acusa, comete muchos abusos... que ella como dueña de dicha casa le ha pasado al comisario Pietrapiana mensualmente una subvención que varía entre cincuenta y cien pesos moneda nacional, por habérselo así exigido... [continúa declaración de la regente] (que el comisario)... en compañía de varios amigos suyos, entre ellos el Sub Comisario Dn Juan Bizot, Francisco Perelli, Crisólogo Castro, Federico Spurr, y muchos otros abren violentando las puertas de las piezas de las mujeres pensionistas, estando o no enfermas, las obligan a permanecer con ellos en la sala de baile donde se divierten hasta avanzadas horas de la mañana..." ${ }^{27}$

23 El Código Rural condenaba la ostentación de armas, ver María E. Argeri y Sandra Chía: "Resistiendo a la Ley: Ámbitos 'peligrosos' de sociabilidad y conducta social. Gobernación del Río Negro, 1880-1930”, en Anuario IEHS, 8, Tandil, Buenos Aires, 1993.

24 Ver Argeri, María E.: "Subordinación estatal, institución policial y violencia. Territorio Nacional del Río Negro, 1880-1930”, ponencia presentada en el V SOLAR, Sâo Paulo, abril de 1996 (en prensa).

25 AHPRN, Policía, Exp. 13049/1924. Resultado de la inspección policial en Maquinchao.

26 Ibídem, Policía, UD 12202/1907. Corresponde al distrito de Adolfo Alsina.

27 Ibídem, Policía, UD 15768/1910. 
Asimismo, siendo el personal policial usuario de este servicio impedía por todos los medios su clausura:

“...una vez llegado este empleado a Roca [Se trata de un comisario enviado a investigar un delito de otro comisario]... informó entre otras cosas, que el comisario Rivas en completo estado de embriaguez, se encontraba en compañía de varios agentes en el prostíbulo, y en circunstancias que varios soldados bailaban, se les ocurrió sacarlos afuera a golpes de puño..." ${ }^{28}$

“...he llegado aquí [Buena Parada] con unos amigos del Ferrocarril Sud de paseo y hallamos el pueblo alarmado por dos comisarios, Carballo y Carranza que están ébrios en un prostíbulo y hacen fuego sobre quien se acerque...” ${ }^{29}$

\section{Pero la aparente permisividad llevaba a frecuentes abusos:}

“... recurrí en queja al Juzgado de Paz donde he levantado una protesta quejándome también al Presidente de la Comisión Municipal por los abusos que comete el comisario que valido de su autoridad saca las mujeres de la casa y las lleva al local de la casa municipal donde habita..." ${ }^{30}$

En otros casos, las disputas llegaban a provocar un conflicto de poderes, resultando la regente del prostíbulo la autoridad del pueblo... El siguiente caso muestra la disputa entre el dueño de un prostíbulo (Carmelo Sabino) y el comisario (Lessieux) que le arruinó el negocio:

“...el Sub Comisario Lesieux por repetidas veces me obligó a que manifestase a la concubina que vivía conmigo la idea de poner un café de camareras... me permitiría dicho establecimiento sin patente... cuando llegó otra mujer propúsole de ponerle por su cuenta una casa análoga... vergonzoso es señor Jefe que un Subcomisario de nacionalidad francés obligando a un argentino honrado y laborioso a emigrar de una localidad en la cual trabajó, y más vergonzoso es que dicho funcionario posee un café camareras como es público y notorio y viva con la que figura al frente de dicho establecimiento y ésta ordena a los agentes tal y cual cosa, con una palabra sea la verdadera autoridad del pueblo...” ${ }^{31}$

Este caso llega finalmente a la gobernación, y luego de enviar la habitual inspección de la jefatura, el comisario de —origen francés- es suspendido de su cargo:

“...Considerando: 1. Que está probado las relaciones inmorales que mantenía el Subcomisario Lessieux con las pupilas de la casa de lenocinio. 2. Que esta funcio-

\footnotetext{
28 Ibídem, Policía, UD 4635/1901. Nota enviada por el jefe de policía al gobernador.

29 Ibídem, Policía, UD 13646/1908. Telegrama de un poblador al gobernador.

30 Ibídem, Justicia Letrada, Exp. 562/1906. Queja de la dueña del prostíbulo de Buena Parada, Carolina Rudasevsky.

31 Ibídem, Gobernación, Exp. 2217/1919. Escándalo en Maquinchao.
} 
naba bajo su amparo directo, percibiendo dinero en compensación a su protección. 3... que el caftán (sic!) Carmelo Sabino, figuró en el personal subalterno de la Comisaría de Maquinchao sin prestar servicio y sin percibir la totalidad de los haberes... haciendo partícipe de una parte de los haberes del Subcomisario...[.] El Gobernador Interino del Territorio Resuelve... Art. 2. Suspender en sus funciones, sin goce de sueldo, al Subcomisario Lessieux, solicitándose la inmediata separación del cargo, por inmoralidad y elevándose estos antecedentes al Ministerio del Interior...”. ${ }^{32}$

Este caso es paradigmático, ya que muestra las relaciones ambiguas que se establecían entre los distintos pobladores: cadenas clientelares que se articulaban y desarticulaban, concubinatos temporarios con las pupilas, imposición de la ley personal amparada en las ordenanzas públicas. La red local de poder se articulaba siempre en torno al ejercicio de la fuerza, cuya legitimidad quedaba, siempre, a mitad de camino entre la violencia privada y la violencia pública.

Por esto, una fluida comunicación epistolar existió siempre entre los gobernadores civiles ${ }^{33}$ y los vecinos "decentes" de cualquier pueblo del Territorio Nacional del Río Negro. Los más diversos motivos se explicitan en esa correspondencia, dejando al descubierto las confrontaciones que afectaron a la constitución del poder político territorial. ${ }^{34} \mathrm{El}$ uso del telégrafo y del correo venía a suplir, por aquellas décadas, el rol que desempeña la representación formal. En efecto, esta mediación con el poder estatal territorial no existía para la mayor parte de los pobladores. En otros casos, los menos, recién comenzaban a constituirse los poderes municipales. De esta práctica política, vinculada a la comunicación directa con los poderes públicos, quedó una amplia documentación que, analizada en sí misma o en relación con otras fuentes, permite enriquecer el análisis de los procesos sociales. A través de estas cartas y telegramas se manifiestan las confrontaciones previas al establecimiento de las nuevas normativas, los intereses contrapuestos, los acuerdos y las instancias de negociación en los diferentes puntos del territorio, las áreas de competencia entre los distintos poderes públicos, las instancias de su articulación interna y la dinámica en la construcción del poder real, en ausencia de una sociedad civil que comienza a perfilarse al final del período que se analiza.

32 Ibídem, Registro Oficial, 4 de julio de 1919, pág. 226

33 En el Territorio Nacional del Río Negro el período de gobiernos civiles se inicia en 1898.

34 La documentación utilizada corresponde a los Archivos de Gobernación, Policía y Justicia del Territorio Nacional del Río Negro. Se compone, sobre todo, de cartas y telegramas de circulación interna y reglamentaciones oficiales y, en menor medida, de expedientes judiciales. 


\section{Consideraciones finales}

De la lectura de la correspondencia gubernamental conjuntamente con el análisis de las notas periodísticas, los reglamentos territoriales, las leyes y decretos nacionales y los alegatos de los funcionarios judiciales, se desprende que, entre 1890 y 1920, la cuestión de la moral pública fue una instancia de permanente conflicto y renegociación. Las diferentes normativas que, a nivel territorial, pretendían regular el comportamiento público y privado llevó al choque de intereses contrapuestos. No obstante, la imposición de cualquier medida que afectase a la moral pública era competencia directa del gobernador, que reglaba las pautas de comportamiento por medio de ordenanzas y reglamentaciones, en tanto funcionario del poder ejecutivo federal. También, a pesar de las distancias y la escasa población del territorio, el ejército y la Justicia Letrada eran los representantes materiales de un orden que lentamente iba imponiéndose sobre los intereses individuales, rescatando para sí el monopolio de la violencia fundado jurídicamente.

Por tanto, la reglamentación de la prostitución y el disciplinamiento de las mujeres de "bajo pueblo" deben entenderse como dos aspectos inscritos dentro del proceso de control de la violencia por parte de los organismos del estado. La violencia física y simbólica, al mismo tiempo que redefinía el género, delineaba una nueva configuración de poder, organizando la vida cotidiana en el marco de una profunda transformación cultural.

Se habían establecido, de esta manera, los nuevos parámetros de la relación subordinación-sumisión. Y la violencia con que se ejercía la coacción física se inscribía dentro de los parámetros legales, porque la organización social aparece al mismo tiempo como el producto de la violencia y como su justificación, porque solamente la violencia institucionalizada permite a los dominantes prolongar su dominación. ${ }^{35}$

35 Garnot, Benoit: Le peuple au siècles des Lumières, París, 1990, pág. 87. 